\title{
Promoting Inclusive Entrepreneurship for Marginalized Community in Post Pandemic Situation
}

\author{
Kisslay Anand \\ Swaniti Initiative
}

Since COVID-19 was first discovered, it has had ripple effects with devastating impacts on global economies and supply chains. It has once again highlighted the disproportionate concentration of economic opportunities in country's urban areas. The solution lies in embracing the future and working towards strengthening the economy through an inclusive approach and focus on creating entrepreneurs from marginalized communities. Over the last decade there has been some increase in number of Scheduled Castes and Scheduled Tribes owned enterprises, these need to increase substantially to enable the socioeconomic empowerment of the marginalized communities. To achieve the vision Government of India has proposed schemes with special focus towards the inclusion of marginalized communities and regionally under-represented areas in entrepreneurship development programs. The major focus of the current study is to determine the challenges faced by entrepreneurs from marginalized communities against the backdrop of the pandemic and explore avenues to ensure their economic sustainability.

Keywords: entrepreneurship development, marginalized communities, India

\section{INTRODUCTION}

It is important to re-establish faith in open markets in order to realize the benefits of globalization in the digital era. Rising socioeconomic imbalance within countries, for example, has had a detrimental influence on the availability of infrastructure support in the market. Localization of job possibilities is important, but it isn't the only issue contributing to a lack of faith in free markets. It may be discrete, with regional variation, based on the type of industries and their structure, closeness to markets, support for innovation, types of infrastructure facilities, and skilled labour available in the local market. In terms of production function, market traction, revenue, and inclusiveness, urban regions, and towns with varying levels of business support infrastructure face a variety of problems. The expansion of the inequality gap may lead to a slowing of the economy's growth trajectory. As a result, marginalized communities' buying power is weakened, and access to education is limited, limiting their capacity to take advantage of market possibilities, and leaving them behind in essential skill sets. The Organization for Economic Cooperation and Development (OECD) has developed a Policy Action on Inclusive Growth structure to assist countries in maintaining and distributing the benefits of a growing economy in a balanced manner. Through a dashboard of predictors to assess growth creation and inclusiveness, the created framework provides various policy outcomes that might enhance growth inclusivity. The proposed framework detects various policy outcomes that might promote inclusiveness in growth by using a set of predictors to analyse development on growth and inclusivity. Three Sustainable Development Goals (SDGs) focusing on 
inclusive entrepreneurship and reducing inequality have been established. These include infrastructure and industrial innovation, decent jobs and economic development, and decreased disparities.

Since the implementation of the Scheduled Caste Sub Plan in the Sixth Five Year Plan, the Indian government has been working to increase the threshold of equality. With the change of markets to a more competitive setting, adjustments have been adopted time and time again. Digitalization and entrepreneurship are crucial in offering up new avenues for growth that are more inclusive. Entrepreneurial prospects have increased as access to information and global markets has improved. The Indian entrepreneurial ecosystem is entering its next phase, raising the bar, and levelling the playing field for everyone. The ecosystem is now equipped to nurture viable companies through inclusive entrepreneurship interventions by extending involvement to underrepresented communities and employing social capital to establish stronger foundations. Standup India is one of the greatest proponents of inclusive entrepreneurship has broadened the scope of regional initiatives.

Inclusive economic growth enables opportunities for all the sections of society and leads to sharing of prosperity amongst them. It involves both monetary and non-monetary benefits. State policies bringing inclusiveness does not only decrease inequality with marginalized communities but also brings sustainability in the growth curve. Such policy interventions further play an important role in globalization and digitalization affecting local markets and adding to competitive pressures on employment, production, services, and opportunities.

The Ministry of Skill Development and Entrepreneurship (MSDE) was established in 2014 to coordinate and oversee all professional development programmes offered by these many departments. The MSDE directly regulates four skill development initiatives operated by MSDE nodal agencies: Pradhan Mantri Kaushal Vikas Yojana (PMKVY), STAR, UDAAN, and Vocationalization of Education. The flagship initiative of the ministry, PMKVY, commenced in 2015 with a budget of Rs. 1500 crore. The government has also established a National Skills Qualification Framework to streamline technical and vocational training and bring it in line with industry demands and worldwide norms (NSQF). In addition to these measures, the central government has created new entities such as the National Skill Development Agency (NSDA) and, as a result, the National Skill Development Fund (NSDF). These actions have resulted in the establishment of a very dynamic institutional structure for the central management and delivery of skills training and vocational programmes (Maithreyi, et al. 2017). Despite these developments, policy structures have remained essentially unequal since 2008, such as the NSDC's implementation of the PMKVY, which effectively favours the distribution of skills training through NGOs and for-profit businesses.

While accepting the unpredictability and precarious nature of entrepreneurial motivations, it is widely acknowledged that the nature of government support, as mentioned above, has a significant impact on how certain impulses are realised in order to start a new business. Entrepreneurial operation requires favourable socioeconomic, political, business, and institutional conditions to be encouraged, facilitated, and enforced (Al-Dajani \& Marlow, 2003).

The necessity of having an inclusive strategy has been highlighted in economic studies by the Organization for Economic Development and Cooperation (OECD). According to the report the conclusions of the studies are shown in figure 1. 


\section{FIGURE 1 \\ RESULTS FOR OECD ECONOMIC STUDIES}

\section{For Marginalized Business Creation and Nurturance}

-Inclusive growth encourages organizational structural improvements and the spread of technology to smaller businesses.

-Encourage firms and governments to invest in new business and governance models. Policies affecting the labour market and job security.

-Adapt and construct labour market structures and social security systems to accommodate new kinds of employment.

-Implement well-designed commodities and labour market laws for fair trade, as well as insolvency regimes that do not obstruct company reorganization or penalize business failure.

-Stimulate regional development policies that encourage the spread of innovation between regions, as well as policies on housing and land use that allow for resource reallocation within and across regions.

For Marginalized Employment Generation and Protection

-Encourage career mobility and opportunities for excellent employment recruitment and retention.

-Encourage the passage of legislation protecting workers' rights.

-Increase the ability of tax and income structures to redistribute wealth.

-Improve the design of tax policies to promote inclusive growth and long-term earnings.

-Align strategies outside of climate policy frameworks to create new markets and jobs.

\section{CHALLENGES TO INCLUSIVE ENTREPRENEURSHIP GROWTH IN INDIA}

Any constructive change, particularly one that promises to reorganize the society and replace its foundations, is rejected. People who lost privileges were taken aback, and others who gained rights had no idea what had happened and were unprepared to reap the benefits. The individuals in power took advantage of this instability, and their prejudices began to creep in, resulting in marginalized people becoming secondclass citizens post-independence.

Consider two of the Indian state's most powerful organs: the executive branch, which implements the government's programmes and policies, and the Reserve Bank of India, which regulates financial access to the poor.

The executive or bureaucracy has remained the most significant hindrance to the development of marginalized populations, not only because of its apathy, but also because it views reservation policies as a violation of their own rights. They have ensured that all policies affecting SCs and STs have failed since independence. These plans, which have been implemented in the previous ten years to broaden the horizons of entrepreneurship, are no exception. Let's look at its shortcomings:

The 4 percent share mentioned in the Public Procurement Policy (2012) is a purchasing preference strategy rather than an affirmative action policy. It means that the SC/ST vendor meets the lowest pricing 
criterion, thereby putting the newcomer on par with the established firm and ignoring the operating cost differential. This explains the entrepreneurs from marginalized communities' lack of interest. According to procurement data from 2017-18, six years after the policy's adoption, the proportion of procurement from MSMEs owned by SC/ST entrepreneurs is 0.01 percent, or Rs 442.52 crore, out of a total of Rs $24,226.51$ crore from MSMEs.

Second, a Venture Capital Fund was established in 2014 to address the banking system's reliance on collateral, which operated as a barrier for first-time SC/ST entrepreneurs. The VCF was created by the bureaucracy to serve as debt support against the collateral, but at a lower interest rate. Ironically, it ended up causing the very problems it was designed to eliminate.

Third, the directional goal of Stand-Up India (2016) was to incorporate SC, ST, and women entrepreneurs in each bank branch. An RTI filed by The Indian Express found that the banking system had given Stand Up India loans to 5,852 SC applicants, 1,761 ST individuals, and 33,321 general-category women after 17 months of operation. As of March 2020, the ratio has remained unchanged, with women receiving 81 percent of all loans sanctioned. It was for this reason that women and SC/STs were lumped together in the plan.

Land, in addition to cash, becomes a critical condition for SC/ST entrepreneurship because it can be mortgaged with traditional financial institutions. In 2016, most states announced a policy of reserving plots in their respective industrial areas in honour. Maharashtra, for example, has set aside $20 \%$ of its land, whereas Karnataka has set aside 22.5 percent. It quickly became an implementation issue because the reservation was based on the number of plots rather than the size of the plots. As a result, irrespective of the entrepreneur's size demand, the smallest plots were designated for the SC/STs. As a result, many SC entrepreneurs would be unable to take advantage of the programme.

The Reserve Bank of India, as a state-run institution, is yet another failed institution for SC/STs. The sole financial inclusion policy it has implemented is Priority Sector Lending (PSL). However, post-1991 PSL committees, including as the C Narasimhan Committee, M V Nair Committee, and N Mor Committee, sought to weaken PSL regulations, resulting in scheduled commercial banks failing to fulfil their targets and the RBI turning a blind eye to the breach.

The RBI has ordered that bank evaluate PSL at the board level every six months to assess consolidated lending to the marginalized. RBI, on the other hand, does not collect data at a granular level. As a result, there is no credible data on the extent to which SC/STs have access to credit. Records of receipt, sanction, rejection, and disbursement should be supplied to the investigating agency, according to PSL's standard guidelines. The Reserve Bank of India has yet to issue a report analysing the reasons for the refusal of loans to $\mathrm{SC} / \mathrm{ST}$ entrepreneurs and recommending any remedial measures.

\section{THEORETICAL FRAMEWORK FOR FOCUS INTERVENTIONS POST PANDEMIC}

This epidemic is not only a serious task, but also a potential opportunity for entrepreneurship education and training. While online learning has been increasingly essential in education over the last 20 years, it has lagged behind, particularly in entrepreneurial education. While online entrepreneurship education is not new, it has yet to gain widespread acceptance, in part because current entrepreneurial education models stress active learning, real-world exposure, and experience-based approaches (Kassean et al., 2015; Neck \& Green, 2011; Neck et al., 2014). The resources and strategies to close this gap are beginning to emerge, with traditional textbook publishers providing significantly more learning materials, private companies developing significantly better online experiential learning curricula, and simulation providers increasingly providing enhanced options. Many entrepreneurship educators are skeptical about the discipline's ability to effectively teach entrepreneurship and online skills on a large scale, as evidenced by these diverse choices, and years of additional curricular and co-curricular pedagogical development and creativity are required to alleviate concerns. As a result, only drastic factors are likely to make it meaningful for the needle to move more and more business classrooms online. We argue that the COVID-19 pandemic will push us to deal with this issue with an increased sense of urgency. 
Several research from various regional contexts were cited in order to grasp the urgency of the situation. Any socioeconomic catastrophe has the greatest impact on the world's poor and underprivileged communities. Furthermore, the economy is in recession, and firms are experiencing cash issues, which puts a strain on small business owners and staff. As a result, in addition to economic reforms, community development and mobilization for long-term sustainability are critical. Specialized entrepreneurship development training programmes that target market trends and skill marginalized entrepreneurs will enable them to take advantage of market opportunities.

According to a survey conducted by PRATHAM for NITI Aayog, there is a growing desire among people in rural and semi-urban areas (about 70\%) to become self-employed entrepreneurs. Being more selfreliant is the most recent way to serve the country and contribute to its rebuilding individually. The new self-sufficient India, on the other hand, will require not just entrepreneurs selling 'Made in India' items, but also people on a vast scale to assure successful execution. As a result, entrepreneurship must be fostered in locations with harsher living conditions so that marginalized parts of Indian society can take advantage of emerging MSMEs prospects. Micro-entrepreneurship is becoming more widely acknowledged as a viable strategy of reducing poverty and generating revenue in India, particularly in rural areas.

Members of the SC/ST community are among the marginalized in Indian society, with limited access to skills and education and a need for encouragement to realize their hidden potential. Training, education, and counselling can help to create the optimal atmosphere for people who are goal-oriented and entrepreneurial.

The epidemic has pressed the fast-forward button, hastening the adoption of new technology. In this precarious time, it has also exposed the digital vulnerabilities of marginalized communities and networks, such as craftspeople. Online training programmes for artisans and micro-entrepreneurs are needed to help them sell their items using digital resources. Apart from inputs in the areas of modernizing designs, market access, and financing linkages, today's micro-entrepreneurs must be familiar with displaying their products on both physical and virtual platforms.

FIGURE 2

\section{ECOSYSTEM FOR RIGHT TO EQUAL OPPORTUNITIES}

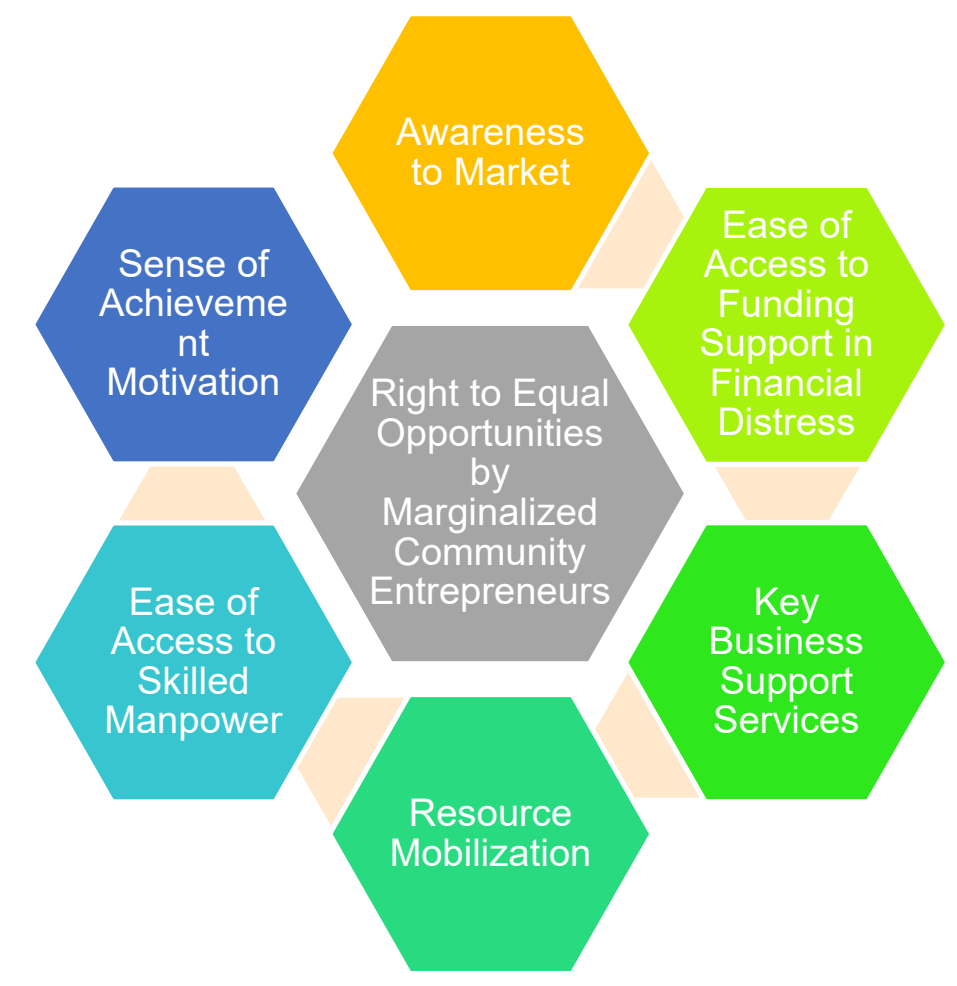




\section{FIGURE 3}

\section{ADAPTED FROM OECD FRAMEWORK FOR INCLUSIVE GROWTH}

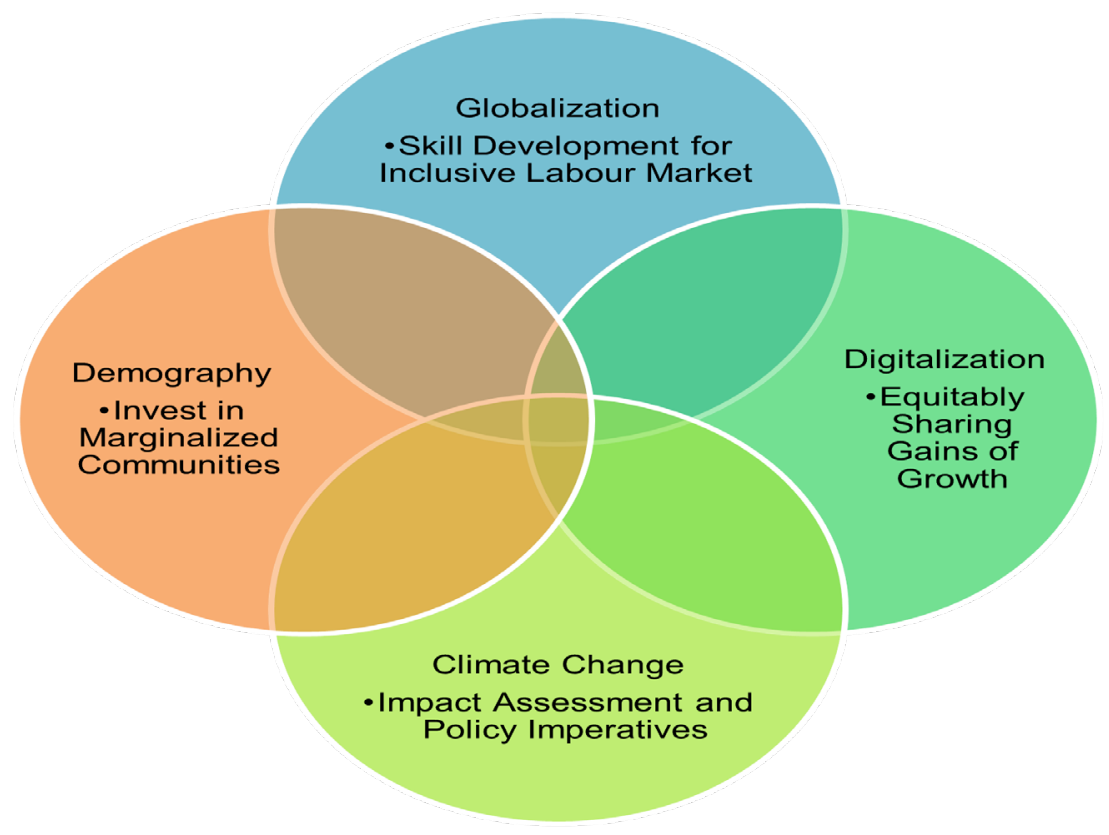

India now needs to accelerate its entrepreneurial drive with openness and diversity, fueled by technical breakthroughs and the spirit of resilience. In the context of globalization, digitalization, demographics, and climate change, the following framework in figure 3 additionally suggests interventions to cope with the changing dynamics.

\section{CONCLUSION}

Entrepreneurship allows diverse underprivileged groups to establish their own permanent source of income and, as a result, give back to the communities from which they originated. It encourages a proactive attitude to local, regional, and worldwide engagement, which is not usually given to individuals who are denied a voice in society. Many strategies are used on a daily basis to encourage marginalised people to pursue entrepreneurship, but what counts most is that these initiatives strive to improve the basic conditions of high-risk groups with the following objectives:

- Improve job prospects for the poor, disadvantaged, and marginalised by providing access to enterprise development skills training.

- Using newly learned skills, empower underprivileged groups to start or develop their enterprises.

- Establish and strengthen networks for implementing social safety net services, working capital providers, and participants from vulnerable groups to create an enabling climate for entrepreneurship.

These are objectives that could aid in the development of communities that can support those who are often left behind. To provide a foundation for the underprivileged to advance in their own communities, a set of standards is required. Individuals will be given the capacity to create their own opportunity by encouraging women, immigrants, refugees, the disabled, youth, and other high-risk populations to participate in entrepreneurship. 


\section{REFERENCES}

Al-Dajani, H., \& Marlow, S. (2013). Empowerment and entrepreneurship: A theoretical framework. International Journal of Entrepreneurial Behaviour \& Research, 19(5), 503-524. https://doi.org/10.1108/IJEBR-10-2011-0138

Bihar Startup Policy. (2017). Retrieved from www.startup.bihar.gov.in

Credit Guarantee Scheme for Stand Up India (CGSSI). (2016). Ministry of Finance, Government of India.

Department of Public Enterprises, Ministry of Finance, Government of India. (2012). Procurement Policy for CSPEs. Retrieved from https://dpe.gov.in/guidelines

Fink, M., Lang, R., \& Richter, R. (2017). Social entrepreneurship in marginalised rural Europe: Towards evidence-based policy for enhanced social innovation. Regions Magazine, 306(1), 6-10.

Gujarat Industrial Policy. (2015). Scheme for availing assistance to startups/ innovator. Retrieved from www.startGujarat.in

Kuckertz, A., Brändle, L., Gaudig, A., Hinderer, S., Reyes, C.A.M., Prochotta, A., \& Berger, E.S. (2020). Startups in times of crisis-A rapid response to the COVID-19 pandemic. Journal of Business Venturing Insights, e00169.

Maithreyi, R. (2017). Skills education and workforce preparation: Examining the disconnects between policy intentions and outcomes in India. Bangalore: Centre for Budget and Policy Studies.

Ministry of Electronics \& Information Technology, Government of India. (2014). Andhra Pradesh Innovation \& Start-up Policy. Retrieved from https://meity.gov.in/

Ministry of Skill Development and Entrepreneurship (MSDE). (2016). Report of the Committee for Rationalization and Optimization of the Functioning of the Sector Skill Councils. Committee for Rationalization and Optimization of the Functioning of the Sector Skills Councils.

MSME. (2016). Odisha Startup Policy. Retrieved from http://www.msmeodisha.gov.in

OECD. (2018a). Opportunities for all: OECD Framework for Policy Action on Inclusive Growth. Policy Brief. Retrieved from http://www.oecd.org/inclusive-growth

OECD. (2018b). The framework for policy action on inclusive growth (pp. 14-37). Meeting of the OECD Council at Ministerial Level. Paris.

RoyChowdhury, S., \& Upadhya, C. (2020). India's Changing Cityscapes: Work, Migration, and Livelihoods. Institute for Social and Economic Change \& National Institute of Advanced Studies.

Student Startup \& Innovation Policy (SSIP). (2016). Retrieved from www.ssipgujarat.in

Venture Capital Fund for Scheduled Castes. (2014). Supporting Ideas and Venture. Ministry of Social Justice and Empowerment, Government of India. Retrieved from https://www.vcfsc.in

WEF. (2017). The Inclusive Growth and Development Report. World Economic Forum, pp. 92-101. Geneva. 